\title{
O tratamento dado ao vocabulário nos métodos de ensino: levantamento e análise de atividades
}

RESUMO

Monica Jessica Aparecida Fernandes Yamamoto monicaaif@yahoo.com.br Universidade
Paulo, Brasil.

\section{Junko Ota}

junkoota@usp.br

Universidade de São Paulo (USP), São Paulo, Brasil.
Esse artigo trata de questões relacionadas à aquisição de vocabulário em L2, com ênfase nas atividades realizadas em sala de aula para promover o desenvolvimento da competência lexical dos aprendizes. A partir de uma pesquisa bibliográfica, descrevemos quatro métodos de ensino, destacando as atividades voltadas à aprendizagem de vocabulário. Em seguida, analisamos essas atividades quanto a sua colaboração para a construção de um repertório rico de vocabulário. Os resultados indicam que as atividades contextualizadas são as que mais contribuem para o desenvolvimento da competência lexical. Contudo, as atividades semi-contextualizadas se mostram mais interessantes para os níveis iniciais em decorrência do limitado domínio do léxico comum a essa fase da aprendizagem.

PALAVRAS-CHAVE: Aprendizagem de Vocabulário. Métodos de Ensino. Competência Lexical. 


\section{INTRODUÇÃO}

Aprender uma língua estrangeira ${ }^{1}$, doravante $L E$, é uma tarefa trabalhosa e que demanda tempo e dedicação. O objetivo da empreitada é o desenvolvimento de uma competência comunicativa que habilite o aprendiz a manejar os vários aspectos da língua-alvo, de acordo com as exigências da situação comunicativa.

O vocabulário, um dos elementos desse complexo sistema, é apontado como uma das principais dificuldades na aprendizagem de uma LE. No entanto, por muito tempo, não recebeu a devida atenção, sendo negligenciado em virtude da priorização do ensino da gramática e da fonética da língua-alvo.

Embora houvesse um reconhecimento de sua importância, vemos que o ensino de novas palavras tendia a ser conduzido de forma assistemática, sem planejamento e controle, ação resultante da crença de que um trabalho pontual é desnecessário, já que o vocabulário parece ser adquirido naturalmente com o tempo. Sobre o assunto, Candlin no prefácio do livro Vocabulary and Language Teaching (CARTER; MCCARTHY, 1988), dizia que o ensino de vocabulário não era considerado uma área independente das outras, estando sempre vinculado à leitura e à escrita, por isso não tinha uma identidade própria. A situação começa a mudar a partir dos anos 80 , momento em que se registra um crescente número de publicações com temas relacionados ao papel do léxico no processo de aquisição ${ }^{2}$ de segunda língua.

Pretendemos aqui apresentar algumas dessas pesquisas, com o objetivo de estabelecer um quadro teórico que nos possibilite avaliar os procedimentos de ensino de vocabulário utilizados no Método Gramática-Tradução, no Método Direto, no Método Áudio-Lingual e na Abordagem Comunicativa.

O artigo está dividido em cinco partes: introdução, apresentação das pesquisas relevantes para nosso trabalho, descrição dos métodos/levantamento das atividades, análise e conclusão.

As atividades serão classificadas em quatro tipos diferentes, dentro de um continnum de contextualidade, e avaliadas quanto ao nível de conhecimento que proporcionam sobre as palavras. Além disso, também será avaliado em que medida colaboram para o desenvolvimento de uma competência lexical composta por um conhecimento rico de vocabulário. As teorias subjacentes a essas tarefas são discutidas na segunda parte.

Existem várias metodologias e abordagens de ensino de $L E$, mas escolhemos os citados acima para fazerem parte desse trabalho por considerarmos que estes sejam representativos na história do ensino-aprendizagem de línguas. Usamos o modelo proposto por Richards e Rodgers ${ }^{3}(1986$, p.28) para descrevê-los em seus níveis de abordagem, organizacional e procedimental. 0 trabalho realizado por Larsen-Freeman (2003) de descrição das técnicas e princípios dos métodos de ensino por meio de observações de aulas reais de $\mathrm{ESL}^{4}$ forneceu o corpus para o levantamento das atividades comumente aplicadas em cada um dos métodos, conforme poderemos ver na terceira parte.

Na quarta parte temos a análise, que está teoricamente embasada nas contribuições de Oxford e Crookall (1990) e de Nation (1990). A primeira nos ajudou no trabalho de classificação das atividades e o segundo nos ofereceu um modelo de conhecimento lexical para avaliação das atividades. 
A última parte do artigo é a conclusão, onde tecemos as observações finais a respeito do tema.

\section{O QUE SE PESQUISA SOBRE O ENSINO DE VOCABULÁRIO?}

A partir da década de 80, finalmente o vocabulário ganha espaço e torna-se um tema recorrente nas pesquisas sobre aquisição de L2. Uma das questões que foram amplamente abordadas é a relação entre o conhecimento lexical e o desempenho em leitura em LE. Na década de 90, Nation (1990) realiza um estudo na tentativa de elaborar uma lista de palavras da língua inglesa que os aprendizes precisam saber para atingir um nível satisfatório de leitura de textos. Sua conclusão foi de que 2000 palavras são de alta frequência, sendo as demais classificadas como técnicas, acadêmicas e de baixa frequência, e que o conhecimento lexical do aprendiz deve abranger as palavras de alta frequência e expandir de acordo com os interesses para com a língua-alvo (NATION, 1990). Posteriormente, Laufer (1997), entre outros, reafirmam que um nível limiar de vocabulário é indispensável para a compreensão em leitura em LE. Segundo a autora, uma competência lexical defasada dificulta o uso de técnicas de leitura que dependem de um domínio vocabular básico para sua aplicação. Na tentativa de delimitar a natureza do limiar, a autora advoga que as palavras que devem compor esse nível de vocabulário são aquelas passíveis de reconhecimento automático, independente de contexto (ibidem, 1997). Como podemos ver, Laufer e Nation se preocupam apenas em definir uma extensão do limiar, no entanto, Scaramucci $(1995$, p.57) sugere uma caracterização mais completa do nível básico de vocabulário. A autora afirma que uma competência lexical deve ser formada por um conhecimento rico de vocabulário ${ }^{5}$, termo cunhado pela primeira vez por Richards (1976), que contemple o domínio de todas as dimensões da palavra (pragmático-discursivo, sintático, morfológico e fonológico).

Outra questão abordada por muitos autores é a definição do que é palavra. Gattolin $(1998$, p.48) apresenta em sua dissertação de mestrado as definições de Leech (1981), Nation (1990) e Laufer (1997). O primeiro considera que a palavra tem dois significados diferentes: um conceitual, que se refere ao objeto, e um conotativo de caráter indeterminado e aberto. Os outros dois compartilham a ideia de que as palavras devem ser definidas pelo uso, ou seja, palavras que tenham a mesma forma, mas carregam mais de um significado, devem ser contadas individualmente, enquanto que as expressões idiomáticas, embora contenham mais de um item lexical, devem representar uma palavra por expressarem apenas um significado.

O que é conhecer uma palavra é outro tema amplamente questionado. Muitos autores formularam modelos de conhecimento lexical, mas, segundo Scaramucci (1995, p.58), o de Nation (1990, p.30-33) é o mais abrangente de todos. Para o autor saber uma palavra é:

Saber a forma oral de uma palavra;

Saber a forma escrita da palavra;

Saber o comportamento gramatical da palavra;

Saber o comportamento referente à colocação da palavra;

Saber a frequência da palavra; 
Saber a adequação da palavra;

Saber o conceito subjacente ao significado da palavra;

Saber a associação desta palavra com outras relacionadas.

Até o momento, vimos alguns aspectos teóricos da definição de palavra e da aquisição de vocabulário em L2. Vejamos agora algumas publicações que abordam os aspectos práticos, entendidos aqui como os procedimentos e as técnicas de ensino de vocabulário. Com relação aos procedimentos, vemos uma discordância sobre o tipo de instrução a ser dada nas aulas. Krashen (1985) defende que o vocabulário deve ser adquirido de maneira incidental por exposição ao insumo via leitura. Em contraposição, temos Nation e Coady (1988, apud GATTOLIN, 1998, p.39) ${ }^{6}$ que defendem a instrução direta, de forma que a atenção do aprendiz recaia sob o novo vocábulo e haja um esforço consciente para aprendê-lo. Argumentam que, embora a inferência seja uma estratégia importante, essa não pode ser a única técnica utilizada para a aquisição de vocabulário, pois há um risco de o aprendiz não adquirir as palavras que infere, tendo em vista que ao conseguir compreender pelo contexto não se preocupa em conhecer efetivamente a nova palavra

Quanto às atividades usadas nas aulas para o ensino de vocabulário, Gattolin (1998, p.62) afirma haver uma grande variedade e destaca o trabalho de Oxford e Crookall (1990), que as analisaram e as classificaram, dentro de um continuum de contextualidade, em três tipos: descontextualizadas, semi-contextualizadas, contextualizadas. Essas serão abordadas mais detalhadamente na seção destinada a análise.

Apresentamos aqui alguns conceitos de aquisição de vocabulário em L2 relevantes para o propósito de nosso trabalho. A seguir, com base no modelo proposto por Richards e Rodgers $(1986$, p.28) descrevemos quatro metodologias de ensino em seus níveis de abordagem, organizacional e procedimental. A partir do trabalho realizado por Larsen-Freeman (2003) buscamos destacar os procedimentos comuns dessas metodologias que visam a aprendizagem de novas palavras em LE.

\section{DESCRIÇÃO DOS MÉTODOS DE ENSINO}

\section{Método Gramática-Tradução}

O Método Gramática-Tradução, doravante MGT, foi o primeiro a ser utilizado no ensino de LE. Em meados do século XIX, as línguas modernas passam a fazer parte do currículo das escolas europeias e o MGT, até aquele momento empregado no ensino das línguas clássicas, foi adotado para a prática pedagógica nas salas de aula durante o período de 1840 a 1940.

Os princípios que embasam esse método, são de base estruturalista. A língua é concebida como um sistema composto por regras que devem ser aprendidas e memorizadas. A linguagem a ser ensinada é a literária, em detrimento da oral, pois é considerada uma boa amostra da língua-alvo devido à acurácia gramatical. 0 erro não é tolerado, sendo papel do professor corrigir e oferecer aos estudantes as respostas corretas (LARSEN-FREEMAN, 2003, p.17-18). 
O objetivo do método é tornar os aprendizes capazes de ler e traduzir textos literários escritos na língua-alvo. Nenhuma, ou muito pouca atenção é dada ao desenvolvimento das habilidades de produção oral e compreensão auditiva, tornando-se claro que a comunicação não é o objetivo da aprendizagem. Não há por parte dos aprendizes iniciativa para se comunicar e nem interação entre os mesmos.

Para atingir tal objetivo, o domínio dos componentes gramaticais da línguaalvo é considerado essencial. Explicações extensas sobre a gramática, aplicação de regras gramaticais em exemplos e comparações entre as línguas envolvidas fazem parte das técnicas de ensino desse método. As principais atividades são tradução e interpretação de textos literários e são completamente controladas pelo professor. O principal parâmetro para avaliação do aprendiz é o desempenho na realização de traduções de uma língua para a outra

A L1 é usada sem nenhum impedimento para explicar e traduzir, adotando a posição de mediadora e sistema linguístico de referência para a aquisição de uma L2 (STERN, 1983 apud RICHARDS; RODGERS, 1986) 7.

Essas são as principais características do MGT, mas deixamos por último a descrição das técnicas que se voltam prioritariamente ou parcialmente ao ensino de nosso objeto de estudo: o vocabulário.

Larsen-Freeman (2003, p.19-20), após acompanhar uma aula conduzida por um professor adepto do MGT, teceu várias observações com o intuito de apontar e localizar na prática os procedimentos e princípios inerentes a esse método.

Dentre as nove técnicas levantadas, quatro são atividades que objetivam o estudo do léxico da língua-alvo, sendo elas:

\section{Sinônimos e antônimos}

Atividades como localização de antônimos de uma lista de palavras no texto e definição de palavras do texto com o uso de sinônimos.

\section{Preenchimento de lacunas}

Consiste na atividade de preencher adequadamente lacunas em frases com o novo vocabulário ou algum item gramatical específico.

\section{Memorização}

Memorização de listas de palavras na língua-alvo e seus equivalentes na língua materna.

\section{Formulação de frases}

Os aprendizes produzem frases usando o vocabulário aprendido na aula.

Destacamos acima apenas as atividades que se ocupam exclusivamente com o estudo das palavras, para posteriormente realizarmos a análise prevista nesse artigo.

O MGT imperou por cem anos e ainda hoje é usado em muitos contextos de ensino de LE, mas sempre foi alvo de muitas críticas. Em seu período áureo, especialistas em ensino de línguas insatisfeitos com os resultados do método - os aprendizes sabiam "sobre" a língua, mas não sabiam usá-la - deram início ao chamado Movimento de Reforma, sendo os principais líderes Henry Sweet, Wilhelm Vietor e Paul Passy. Esses linguistas afirmavam que o MGT não tinha 
nenhum embasamento teórico e defendiam o estabelecimento de princípios metodológicos baseados em análises científicas da língua e estudos da psicologia. Como resultado, observamos uma proposta de mudança brusca no tratamento e nas concepções acerca da língua e do processo de aprendizagem, tais como: valorização da língua falada, treino da fonética, uso de diálogos para introdução de frases usadas no dia a dia, ensino dedutivo da gramática e produção de significado na língua-alvo sem intervenção da L1 (SWEET, 1899 apud RICHARDS; RODGERS, $1986)^{8}$. Alimentado por esses novos princípios, surge o Método Direto, do qual trataremos no tópico a seguir.

\section{Método Direto}

O Método Direto, doravante MD, nasceu na Europa na primeira metade do século XIX e foi difundido nos Estados Unidos por Lambert Sauver e Maximilian Berlitz. O nome é uma representação de sua proposta básica: aprender a línguaalvo de maneira direta, sem intervenção da língua materna (RICHARD; RODGERS, 1986, p. 9).

Os princípios que regem esse método foram delineados durante o Movimento de Reforma. A língua não é mais vista como um sistema a ser dominado, mas sim como um instrumento para a comunicação. Logo, a linguagem oral é valorizada e usada como insumo para o ensino de LE. Aliás, há uma preocupação em oferecer insumos significativos para os aprendizes, por isso os temas para as aulas limitamse a frases e palavras que podem ser usadas no cotidiano. As quatro habilidades são trabalhadas desde o início, mas a oralidade tem uma posição de destaque e deve anteceder qualquer tipo de atividade (LARSEN-FREEMAN, 2003, p. 29).

O objetivo do método é fazer com que os aprendizes pensem diretamente na língua-alvo ao se comunicarem. Desse modo, o uso da L1 é proibido - nem mesmo dicionários são permitidos. As explicações e as palavras novas são introduzidas oralmente na LE em estudo. Para garantir o entendimento, o professor usa figuras, imagens, gestos, teatralizações e objetos reais, mas nunca a tradução. A gramática não é analisada pelos aprendizes, mas aprendida por deduções feitas a partir de exemplos de uso. Os aprendizes são estimulados a falarem espontaneamente e apenas na língua-alvo, mas o professor deve se preocupar em corrigir a pronúncia e os erros gramaticais.

A habilidade oral é trabalhada de forma sistemática, por meio de atividades de pergunta-resposta organizadas em uma ordem crescente de dificuldade. A interação ocorre entre professor-aluno e aluno-aluno, os quais são vistos como parceiros no processo de aprendizagem.

Quanto ao trabalho com o léxico, destacamos a seguir, dentre as observações feitas por Larsen-Freemam (2003, p.30), a única atividade que consideramos estar, pelo menos em parte, envolvida com o ensino de vocabulário:

\section{Preenchimento de Lacunas}

Apesar de já termos discutido essa atividade no MGT, há uma sutil diferença na forma como é realizada no MD. No primeiro, exige-se a colocação de uma palavra a partir de opções dadas, enquanto que no segundo a colocação do vocabulário deve ser feita pela interpretação da frase e de forma livre, ou seja, o 
aprendiz pode preencher a lacuna com qualquer palavra que complete a frase e faça sentido.

Observamos que o MD não tem a preocupação em aplicar atividades direcionadas exclusivamente ao vocabulário, mas emprega uma atenção especial no planejamento de procedimentos que julga viabilizar a aprendizagem do mesmo, como podemos ver a seguir:

\section{Contextualizar as palavras}

Toda palavra nova é apresentada em uma frase para exemplificar seu uso.

\section{Selecionar o vocabulário}

O vocabulário a ser ensinado, em especial nos níveis iniciais, é escolhido cuidadosamente e deve ser simples, útil para a comunicação e de alta frequência.

\section{Instrumentalizar palavras já aprendidas}

As palavras já aprendidas devem ser usadas para aprender novas palavras.

\section{Exigir e produzir enunciados completos}

O professor deve evitar enunciados curtos e solicitar de seus aprendizes frases completas, pois nenhuma oportunidade de prática de uso e contextualização deve ser desperdiçada.

O MD foi utilizado nas escolas regulares da França e da Alemanha para o ensino de línguas modernas e adotado no resto da Europa e nos Estados Unidos apenas nos cursos livres de línguas. Em ambos os casos, sua popularidade começa a sofrer abalos por volta de 1920. Na França e na Alemanha, ocorreu uma flexibilização na aplicação do método, resultando em um ajuste quanto ao controle e a aplicação de atividades com base gramatical. Nos Estados Unidos, a possibilidade de adotá-lo nas escolas regulares foi rejeitada e seu uso se restringiu aos cursos livres de línguas.

Essa recusa é resultado da percepção de algumas características do método que inviabilizam o seu uso em escolas de ensino regular, como por exemplo, a rigidez quanto à proibição do uso da L1, que exige professores nativos ou com alto nível de proficiência e a demanda de tempo para explicar tudo na língua-alvo. No caso específico dos Estados Unidos, os objetivos do método não condiziam com os dos aprendizes, já que esses preferiam aprender a ler e não a falar (RICHARDS; RODGERS, 1986, p.11).

O ensino de línguas nos Estados Unidos seguiu enfatizando a leitura até a Segunda Guerra Mundial (id.). No entanto, o novo cenário político trouxe a necessidade de comunicação em várias línguas e um método que atendesse a esse objetivo, levando ao surgimento do Método Áudio-Lingual.

\section{Método Áudio-Lingual}

A Segunda Guerra Mundial impulsionou uma revolução na área de ensino de línguas nos Estados Unidos. A necessidade de ter pessoas capazes de se comunicar em diversas línguas, em especial nas dos países envolvidos na guerra, levou as autoridades americanas a financiar projetos para a elaboração de um método de ensino de LE rápido e eficiente. 
Em 1950, período pós-guerra, o ensino de línguas recebe novamente uma atenção especial, devido ao aumento de estrangeiros no país para os mais diversos fins, que precisavam aprender o inglês rapidamente. Novos investimentos foram feitos, e após um esforço intelectual de linguistas da época para a elaboração de um método com bases teóricas sólidas, nasce o Método Áudio-Lingual, doravante MAL (RICHARDS; RODGERS, 1986, p. 47).

Os princípios desse método estão fortemente pautados na teoria estruturalista da língua, elaborada por linguistas americanos da década de cinquenta, e na teoria behaviorista de aprendizagem, desenvolvida por R. F. Skinner. Para os estruturalistas, a língua é um sistema composto por três níveis (fonológico, morfológico e sintático), que se combinam estruturalmente para produzir significados e esse processo pode ser observado e descrito. Já a teoria behaviorista de aprendizagem traz ao método a concepção de que o ser humano é capaz de manter um amplo repertório de comportamentos, inclusive linguísticos, aprendidos a partir do processo de estímulo-resposta-reforço (ibidem, p. 48-50).

Como resultado dessa combinação, temos um método que carrega o objetivo de capacitar os aprendizes para a comunicação através da formação de hábitos linguísticos na língua-alvo. $\mathrm{O}$ uso da $\mathrm{L} 1$ deve ser evitado ao máximo, pois se considera que essa interfere negativamente no processo de aquisição. As produções dos aprendizes são uma imitação de modelos fornecidos pelo professor ou por materiais de áudio e são controladas e monitoradas, para que os erros, tanto gramaticais quanto de pronúncia, sejam evitados e não haja formação de maus hábitos. Objetiva-se que os aprendizes consigam usar a língua sem pensar sobre ela, de maneira automática, por isso a gramática é aprendida por analogias estabelecidas a partir de modelos dados, ou seja, de forma dedutiva. As habilidades oral e auditiva são centrais e todos os conteúdos e atividades são inseridos e trabalhados na seguinte ordem: ouvir, falar, ler e escrever. A linguagem oral é valorizada, já que a língua é tida como essencialmente falada.

Diálogos contendo estruturas padrões da língua-alvo são principal tipo de insumo e são memorizados pelos aprendizes, que só usam o livro didático depois de um extenso treino oral de tudo o que está sendo visto na lição. (RICHARDS; RODGERS, 1986, p. 52-56)

O procedimento adotado nas aulas é regular e rígido. Em um primeiro momento, os aprendizes se esforçam para memorizar um diálogo ouvido, mas sem ler. Em seguida, frases do diálogo que contenham estruturas padrões são isoladas para serem treinadas em exercícios orais de fixação. Por fim, são realizadas atividades de leitura e escrita (LARSEN-FREEMAN, 2003, p. 37-42).

No que se refere ao tratamento do vocabulário, ao pensarmos em um ensino sistematizado do léxico, que se preocupe com pontos como frequência, exposição, os vários aspectos da palavra e a própria posição do léxico no processo de ensinoaprendizagem de uma LE, o MAL se mostra pouco engajado com a questão. Devido à importância dada à automatização das estruturas fonéticas e gramaticais da língua-alvo, o tratamento do vocabulário é uma tarefa secundária limitada a memorização por contato, ou seja, a aprendizagem de vocabulário é tratada como um subproduto. Todas as palavras novas são introduzidas de forma controlada e apenas para serem utilizadas nos exercícios de fixação. Considera-se que toda palavra ensinada deve ser mostrada em uso, por isso introduzir vocabulário em grande quantidade sem contextualização não é considerado produtivo. 
A partir da leitura das observações de Larsen-Freeman (2003, p.47-50), arriscamo-nos a destacar duas atividades que, ainda que de maneira indireta, contribuem para a aquisição de vocabulário no sentido de direcionar a atenção do aprendiz especificamente para os novos itens lexicais. São elas:

\section{Exercícios de substituição}

As palavras são encaixadas em um mesmo eixo sintagmático e na mesma posição.

\section{Completar lacunas do diálogo}

Consiste em completar com as palavras adequadas as lacunas do diálogo memorizado anteriormente.

Em ambas as atividades, o foco não está em memorizar as palavras novas ou aprofundar o conhecimento das que já são conhecidas, mas como nessas atividades as palavras são manipuladas de forma isolada, boa parte da atenção dos aprendizes recai sobre elas.

Quanto aos procedimentos realizados durante a aula, notamos uma técnica que consideramos ser benéfica para a aprendizagem do vocabulário:

\section{Utilização de pares-mínimos}

O professor utiliza palavras foneticamente e morfologicamente parecidas para ensinar os sons da língua-alvo, aguçar a compreensão auditiva e aprimorar a pronúncia dos aprendizes. Tomemos como exemplo a língua japonesa: abaasan (avó) e obasan (tia); biyoin (salão de beleza) e byouin (hospital).

Essa técnica proporciona um momento de estudo das características fonéticas e morfológicas das palavras, embora suas dimensões semântica e pragmática sejam contempladas de maneira muito superficial.

O MAL foi amplamente utilizado nas décadas de 50 e 60 . Ainda hoje, muitos professores e cursos de línguas fazem uso desse método. No entanto, seu caráter imitativo e inibidor começou a ser questionado. As situações reais de comunicação diferem das "treinadas" em sala de aula, levando os aprendizes, inaptos em lidar com diálogos imprevistos, a experienciar o fracasso.

Diante do quadro insatisfatório, mais uma vez, estudiosos se dedicaram à busca de novas alternativas para área em questão. Dos anos 50 aos anos 70, surgiram várias propostas metodológicas humanistas como a Suggestopédia, o Silent Way, Community Language Learning, e o Total Physical Response. Apesar de terem tido menos impacto, contribuíram ao trazer princípios revisados e um novo elemento: a consideração de questões afetivas envolvidas no processo de ensinoaprendizagem, inclusive os sentimentos dos aprendizes. (LARSEN-FREEMAN, 2003, p.73). Esses métodos prepararam o terreno para o que viria a seguir: o Movimento Comunicativo no ensino de línguas, culminando no surgimento da Abordagem Comunicativa.

\section{Abordagem Comunicativa}

No final dos anos 60, enquanto o MAL dominava as salas de aula de LE nos manifestação da Abordagem Comunicativa, doravante AC. 
Muitos autores se colocavam contrários às teorias que sustentavam o MAL e propuseram novas concepções sobre a língua e o processo de aprendizagem. Entre eles, temos o sociolinguista Dell Hymes, autor do conceito de competência comunicativa. Para Hymes, a linguagem também é determinada por fatores pragmáticos e sociolinguísticos, sendo a competência linguística (conhecimento da estrutura e funcionamento da língua) apenas um dos saberes necessários para o uso efetivo da língua (RICHARDS; RODGERS, 1986, p.70).

Vale citar também o linguista britânico Wilkins (1976), um dos idealizadores do Ensino de Línguas Situacional, que coloca em discussão a negligência das abordagens vigentes quanto ao tratamento dado às outras dimensões da língua: a funcional e a comunicativa. Ele afirma que por trás do uso comunicativo há dois tipos de significado: categorias nocionais (conceitos de tempo, sequência, quantidade, etc.) e as categorias de função comunicativa (pedidos, convites, etc.). Sua afirmação contribui para a construção do significado do termo comunicativo, assim como proveu bases para a construção de um syllabus nocional-funcional.

A nova proposta metodológica não tinha a intenção de ser um método, cheio de prescrições e regras, mas sim, uma abordagem munida de um conjunto de princípios que poderiam ser usados como norte para o ensino de LE, como veremos nos parágrafos a seguir. (ibidem, p.66).

Segundo os adeptos da AC, a língua deve ser vista como um sistema para se expressar, que tem como funções principais a interação social e a comunicação. Os aprendizes aprendem a língua ao se comunicar e negociar significados, por meio de atividades que precisam ser essencialmente comunicativas, significativas e que envolvam a língua na execução de tarefas. Aliás, o significado é muito importante, por isso a contextualização é indispensável.

O principal objetivo é capacitar os aprendizes a se comunicarem na línguaalvo, desenvolvendo uma competência comunicativa, que inclui não só os conhecimentos de cunho linguístico, mas também os de cunho semântico e pragmático. Nessa empreitada, o professor atua como facilitador para a comunicação e é responsável pela criação de situações que propiciem a comunicação. O aprendiz é considerado o maior responsável pela sua aprendizagem e é posto no papel de comunicador, que mesmo errando deve se esforçar para se expressar, pois o mais importante é a fluência e não a precisão gramatical. $\mathrm{O}$ erro é visto como algo natural ao processo de aprendizagem e deve servir como um guia ao professor, para auxiliar no desenvolvimento de seus aprendizes. (LARSEN-FREEMAN, 2003, p.76).

As quatro habilidades são trabalhadas desde o início, sempre com alguma intenção comunicativa e de forma espontânea. A língua não é estudada de forma analítica, mas o professor não se recusa a dar explicações caso o aprendiz solicite. Evita-se a L1 na medida do possível, mas nada impede seu uso se for mais conveniente para o momento do que a língua-alvo. Os materiais usados nas aulas são livros textos, materiais baseados em tarefas e materiais autênticos, com preferência pelos dois últimos (ibidem, 2003 p.132-133).

A AC propôs muitas mudanças para o ensino de línguas, mas também se absteve no que se refere ao ensino sistemático de vocabulário. Segundo Wilkins (1974, apud ZIMMERMAN, 1997, p. 14) ${ }^{9}$, a única maneira de se dominar o sistema lexical de uma LE é pela exposição considerável a ela. Zimmerman (1997, p.14), completa dizendo que "pouca atenção explícita foi dada ao vocabulário nas 
publicações tanto teóricas quanto metodológicas sobre o syllabus NocionalFuncional" ${ }^{10}$. Vemos, então, que a AC adota a premissa de que as palavras são adquiridas de forma natural e por exposição, dispensando um trabalho pontual com o vocabulário.

A contextualização e o foco no significado são princípios básicos da AC que beneficiam a aquisição do léxico da língua-alvo, mas essa pode ser potencializada se os professores dispuserem mais atenção ao vocabulário, organizando e sistematizando seu ensino.

Abaixo estão descritas as atividades que Larsen-Freemam (2003, p.133-134) observou durante uma aula de inglês. Como mencionado acima, a AC assume que o vocabulário é adquirido de forma natural, assim como ocorre com a L1, portanto todas as atividades desenvolvidas em uma aula realizada via AC servem também ao propósito de promover aquisição de vocabulário. Vejamos:

\section{Sentenças embaralhadas}

As frases de um texto são separadas e embaralhadas para que os aprendizes a reorganizem.

\section{Jogos de linguagem}

Os jogos podem ser projetados para proporcionar a prática comunicativa com o uso de itens linguísticos pré-determinados, inclusive o vocabulário.

\section{Dramatização (Role play)}

São exercícios considerados importantes, porque possibilitam simular comunicação em diferentes contextos e papéis sociais.

\section{História com imagens}

Uma história é criada ou imaginada a partir de imagens.

Ao descrevermos a evolução histórica da área de ensino de línguas, observamos que o interesse em tornar mais fácil e rápido a difícil tarefa de aprender uma LE passou, pouco a pouco, a ser uma questão de grande relevância para pesquisas científicas. Consequentemente, muitas propostas metodológicas surgiram como tentativas para solucionar o problema, cada qual com sua visão do que é língua e do que é aprender. Não foi diferente com o vocabulário, que ocupou, ora posição primária, ora secundária, dentro do processo de ensinoaprendizagem.

Após essa breve exposição sobre os métodos/abordagem de ensino escolhidos para esse trabalho, seguiremos agora para a análise das atividades voltadas para o ensino de vocabulário.

\section{ANÁLISE}

Na seção anterior, levantamos o número total de nove atividades usadas em quatro métodos de ensino para trabalhar o vocabulário. Iremos agora classificar essas atividades em três tipos: contextualizadas, semi-contextualizadas e descontextualizadas (OXFORD; CROOKALL, 1990, p.9). Em seguida, com base no modelo de conhecimento lexical proposto por Nation (1990) faremos uma análise 
de cada uma das atividades com o objetivo de avaliar em que nível contribuem para o desenvolvimento de um conhecimento rico de vocabulário.

O modelo proposto por Nation (1990, p.30-33) determina oito tipos de saberes necessários sobre uma palavra, para que essa possa se integrar a competência lexical do aprendiz na condição de conhecimento rico de vocabulário. Embora seja usado como parâmetro para testes de vocabulário, ou seja, para aferir o grau de conhecimento do aprendiz pré e pós-processo de aprendizagem, aqui o usaremos na análise das atividades utilizadas para promover a aquisição. Dessa forma, pontuaremos quais são os conhecimentos mobilizados durante a execução das atividades e consideraremos que o grau de benefício dessas é proporcional ao número de saberes ativados. Para facilitar a leitura dessa seção, colocamos abaixo novamente, a lista dos saberes:

A forma oral de uma palavra;

A forma escrita da palavra;

O comportamento gramatical da palavra;

O comportamento referente à colocação da palavra;

A frequência da palavra;

A adequação da palavra;

O conceito subjacente ao significado da palavra;

A associação desta palavra com outras relacionadas.

\section{ATIVIDADES DESCONTEXTUALIZADAS}

As atividades descontextualizadas são as que isolam a palavra de qualquer contexto, impossibilitando associações que poderiam ajudar a relembrá-la (OXFORD; CROOKALL, 1990, p.9). A única atividade, das listadas nesse artigo, que se enquadra nesse tipo é a lista de palavras, comum ao MGT.

As listas de palavras são usadas para memorização e podem ser elaboradas em ordem alfabética ou por classe gramatical. Segundo Oxford e Crookall (ibidem, p. 10), os adeptos desse tipo de atividade acreditam que para aprender uma palavra a memorização é o melhor caminho.

A atividade exige o emprego de pouco conhecimento, pois aciona apenas os itens dois (forma escrita) e sete (conceito) do modelo acima. Como não há nenhum tipo de instrução direta prevista, muitas vezes nem mesmo o item um (forma oral) é trabalhado, mesmo no caso de L2 em que a ajuda do professor é necessária para se ter acesso à pronúncia correta das palavras.

Sendo assim, consideramos essa atividade como pouco significativa para o ensino de vocabulário. Contudo, Nation (1990) pontua dois pontos positivos das listas de palavras: estimula a autonomia do aprendiz e possibilita a aprendizagem de muitas palavras, ainda que superficialmente, em um curto período de tempo. Oxford e Crookall (1990, p 10-11) oferecem duas sugestões para torná-las mais proveitosas: fazer com que os aprendizes decidam as palavras que constarão nas listas ou fazê-los dispor as palavras por temas ou tópicos. 


\section{ATIVIDADES SEMI-CONTEXTUALIZADAS}

Retomando Oxford e Crookall (ibidem, p.9), as atividades semicontextualizadas são as que posicionam as palavras em um mínimo de contexto, ou as associam a algo que pode ajudar a relembrá-las. Das nove atividades pontuadas nesse artigo, classificamos quatro nessa categoria, são elas: sinônimos e antônimos, preenchimento de lacunas, substituição e formulação de frases.

A atividade denominada sinônimos e antônimos foi observada em uma aula de um professor adepto do MGT e consiste em indicar sinônimos ou antônimos de palavras. Propicia uma possibilidade de associação, mas o conhecimento desenvolvido por meio dessa atividade é limitado aos itens dois (forma escrita), sete (conceito) e oito (associações). Tendo em conta que o MGT não se preocupa com as habilidades oral e auditiva, o item um (forma oral), provavelmente, não será trabalhado em nenhuma das atividades desenvolvidas nesse método.

A segunda atividade, preenchimento de lacunas, figurou nas aulas que ensinaram via MGT, MD e MAL. Embora a tarefa se resuma a preencher espaços em branco de orações ou diálogos, essa foi executada de forma diferente em cada um dos métodos. No primeiro, as lacunas eram preenchidas com as palavras contidas em uma lista pré-determinada. No segundo caso, não havia uma lista de opções para se escolher a certa, os aprendizes podiam preencher livremente. No terceiro, o trecho que continha as lacunas havia sido previamente memorizado pelos aprendizes e eles deviam recordar a palavra que estava faltando. Em todos os casos, os itens dois, três, quatro e sete são trabalhados, já o item um, apenas nos dois últimos métodos.

A terceira atividade, substituição, amplamente utilizada no MAL, refere-se ao trabalho de trocar uma palavra por outra, sem mudar a frase. $O$ objetivo principal está em treinar uma estrutura, mas por utilizar as palavras, consideramo-la também como uma atividade de vocabulário. Esse exercício é feito oralmente, por isso cumpre com o item um (forma oral) do modelo, mas o item dois (forma escrita) só será alcançado se o exercício for realizado também de forma escrita. Ao substituir as palavras, o aprendiz deverá pensar sobre os itens quatro (colocação), sete (conceito) e oito (associação), graças ao pequeno contexto que a atividade oferece. À primeira vista, pode parecer que essas atividades contemplem também o item seis (adequação da palavra), mas consideramos não ser o caso dado o fato de que a adequação da palavra se refere à escolha de um item lexical de acordo com o contexto de uso. Nessas atividades não há reflexão sobre essa questão de adequabilidade de uso, trabalha-se por apenas questões formais e semânticas da língua.

A quarta atividade, formulação de frases, como o próprio nome diz, consiste em elaborar frases com as palavras novas. Dependendo do esforço que o aprendiz dispensar para a realização da tarefa, quase todas os itens do modelo podem ser contemplados. Para escrever uma frase espontaneamente, ou seja, sem copiar, o aprendiz terá que pensar sobre a forma das palavras (item dois) e as combinações (sintáticas, semânticas e pragmáticas) necessárias para produzir um enunciado com sentido (itens três, quatro, seis e sete).

Como pudemos ver acima, as atividades semi-contextualizadas são bem mais interessantes para o ensino de vocabulário. Consideramos que essas atividades são muito úteis para ensinar as palavras nos níveis iniciais, momento em que o 
aprendiz ainda não possui o mínimo de vocabulário necessário para realizar atividades mais contextualizadas. Embora essas atividades não levem ao conhecimento rico do vocabulário, devemos lembrar que não conhecemos integralmente uma palavra vendo-a apenas uma vez; são necessários vários encontros para conhecê-las por completo, sendo essas atividades uma boa opção para os primeiros encontros.

\section{ATIVIDADES CONTEXTUALIZADAS}

Segundo Oxford e Crookall (1990, p.22), as atividades contextualizadas são as que colocam em uso as quatro habilidades da língua em situações comunicativas autênticas. As únicas atividades que podem ser classificadas dessa forma são as que observamos na aula ministrada via AC. São elas: sentenças embaralhadas, jogos de linguagem, dramatização e história em quadrinhos. Segundo descrição feita por Larsen-Freeman (2003), todas foram realizadas nessas condições.

Os outros dois tipos de atividades (descontextualizadas e semicontextualizadas) levam ao conhecimento de aspectos formais das palavras, mas as propostas aqui se preocupam com os aspectos semântico-pragmáticos. Essas atividades foram aplicadas em uma aula regida pelos princípios da AC, e por isso as palavras são apresentadas em amplo contexto, para que sejam adquiridas de maneira incidental.

De fato, as atividades contextualizadas são as que têm mais potencial para a formação de um conhecimento rico de vocabulário. No entanto, isso só se concretizará se o professor mantiver esse objetivo claro em seus planejamentos, para que haja uma sistematização e um controle do ensino de vocabulário.

\section{CONCLUSÃO}

O vocabulário, embora sempre tenha tido seu lugar no processo de ensinoaprendizagem de línguas, recebeu tratamentos distintos ao longo da história do ensino de LE. Ora mais valorizado, ora menos, o que se manteve estável foi a indiferença quanto à necessidade de sistematização de seu ensino. Planejar e controlar o léxico, independentemente da forma adotada para sua instrução (direta ou indireta), é indispensável. Isso implica em determinar as palavras que se quer ensinar, planejar o número de encontros e a frequência e variar as atividades para que todos os aspectos sejam trabalhados.

A análise realizada nesse artigo indica que as atividades contextualizadas, sendo elas sentenças embaralhadas, jogos de linguagem, dramatização e história em quadrinho, são as mais relevantes para o desenvolvimento de uma competência lexical composta por um conhecimento rico do vocabulário, uma vez que acionam diversos aspectos das palavras durante sua realização. Essas atividades carregam uma visão holística da língua, ou seja, as habilidades e competências são postas em ação de maneira integrada para se atingir o objetivo o principal objetivo: a comunicação. Esse tipo de atividade é comum nas salas de aulas de professores adeptos da Abordagem Comunicativa.

Sobre as atividades semi-contextualizadas, ressaltamos sua relevância no contexto de ensino para aprendizes iniciantes, tendo em vista que atividades 
inteiramente contextualizadas tonam-se inviáveis em decorrência do ainda limitado conhecimento da língua-alvo.

Por fim, concluímos que o ensino sistematizado do léxico deve objetivar o desenvolvimento de um conhecimento rico de vocabulário. Algumas das atividades analisadas nesse trabalho podem servir a esse propósito, além de muitas outras que os professores podem criar, desde que de maneira criteriosa, mantendo claro o objetivo de ajudar seus aprendizes a atingirem uma competência lexical desejada. 


\title{
The treatment given to vocabulary in teaching methods: research analysis od activities
}

\begin{abstract}
This article addresses issues related to vocabulary acquisition in a second language, with emphasis on activities in the classroom to promote the development of lexical competence of learners. We describe four methods of teaching and highlight the activities for learning vocabulary. Then we classify and analyze the activities regarding their collaboration to build a repertoire of rich vocabulary.
\end{abstract}

KEYWORDS: Vocabulary Learning. Language Teaching Methods. Lexical Competence. 


\section{NOTAS}

1 Neste artigo, os termos língua estrangeira (LE) e segunda língua (L2) serão usados para designar a língua que não é a materna, independente do contexto de ensino.

2 Embora Krashen (1981) proponha uma diferenciação entre os termos aquisição e aprendizagem, optamos por utilizá-los indistintamente para se referir ao processo de internalização da LE em contexto formal de ensino.

3 Richards e Rodgers (1986) enquadram as atividades no nível organizacional e as técnicas no nível procedimental, como itens distintos. Contudo, em alguns momentos, utilizaremos a palavra "atividade" (entre aspas) com o sentido de "técnica", por considerarmos a primeira como uma possibilidade da segunda.

4 Inglês como segunda língua.

5 Rich concept of vocabulary.

6 NATION, P.; COADY, J. Vocabulary and reading. In Carter, R.; McCarthy, M. (eds.) Vocabulary and Language Teaching. London: Longman, p. 97-110, 1998.

7 STERN, H. H. Fundamental concepts of language teaching. Oxford: Oxford University Press, 1983.

8 SWEET, H. The practical Study of languages. Reprinted. London: Oxford University Press, 1899.

9 ILKINS, D. Linguistics in language teaching. London: Edward Arnold. 1972.

10 Versão nossa do trecho original: "[...] little explicit attention has been given to vocabulary in either theoretical or methodological publications about notional and functional syllabi."

\section{REFERÊNCIAS}

COADY, J.; HUCKIN, T. (eds.). Second language vocabulary acquisition: a rationale for pedagogy. Cambridge: Cambridge University Press, 1997.

GATTOLIN, S.R.B. O Ensino de vocabulário em língua estrangeira: uma proposta para sua sistematização. 1998. 238f. Dissertação (Mestrado em Linguística Aplicada) - Instituto de Estudos da Linguagem, Universidade Estadual de Campinas, Campinas, 1998.

KRASHEN, S. D. Second language acquisition and second language Learning. New York: Prentice Hall, 1981.

S. D. The input hypothesis: issues and implications. New York:

Longman Inc., 1985.

LARSEN-FREEMAN, D. Techniques and principles in language teaching. 2ed. 
LAUFER, B. The lexical plight in second language reading: Words you don't know, words you think you know, and words you can't guess. In Coady, J; Huckin, T (Orgs.). Second Language Vocabulary Acquisition: A Rationale for Pedagogy. Cambridge: Cambridge University Press, 1997, p. 20-34.

LEECH, G. N. Semamics. 2ed. Harmondsworth: Penguin, 1981.

NATION, P. Teaching and Learning Vocabulary. Rowley, MA: Newbury House, 1990.

NATION, P.; COADY, J. Vocabulary and reading. In: Carter, R; McCarthy, M. (eds.) Vocabulary and Language Teaching. London: Longman, 1988 p. 97-110.

OXFORD, R. \& CROOKALL, D. Vocabulary Language: A critical Analysis of Teaching. TESL Canada Journal, v.7, n.2, 1990, p. 9-30.

RICHARDS, J. The role of vocabulary teaching. TESOL Quarterly, v.10, n.1, 1976.

RICHARDS, J.; RODGERS, T. S. Approaches and methods in language teaching: description and analysis. New York: Cambridge University Press, 1986.

SCARAMUCCI, M. V. R. O papel do léxico na compreensão em leitura em língua estrangeira: foco no produto e no processo. 1995. 357f. Tese (Doutorado em Linguística Aplicada) - Instituto de Estudos da Linguagem, Universidade Estadual de Campinas, Campinas, 1995.

SCARAMUCCI, M. V. R.; GATTOLIN, S.R.B (Orgs.). Pesquisas sobre Vocabulário em Língua Estrangeira. Campinas: UNICAMP, 2007.

WILKINS, D. A. Notional Syllabuses. Oxford: Oxford University Press, 1976.

ZIMMERMAN, C. B. Historical trends in second language vocabulary instruction. In COADY, J.; Huckin, T. (eds.). Second Language Vocabulary Acquisition: A Rationale for Pedagogy. Cambridge: Cambridge University Press, 1997, p. 5-19. 
Recebido: 14 ago. 2015

Aprovado: 28 out. 2016

DOI: $10.3895 /$ rl.v12n25.3054

Como citar: YAMAMOTO, M.J.A.F; OTA, J. O tratamento dado ao vocabulário nos métodos de ensino: levantamento e análise de atividades. R. Letras, Curitiba, v. 18, n. 23, p. 95-113, jul./dez. 2016. Disponível em:

$<$ https://periodicos.utfpr.edu.br/rl>. Acesso em: XXX.

Direito autoral: Este artigo está licenciado sob os termos da Licença Creative Commons-Atribuição 4.0 Internacional.

(c) $\underset{\mathrm{ar}}{(1)}$ 